\title{
Inventory of ticks on dogs in rural areas of the northeast of Algeria and its relationship with influences some ecological and climatic parameters
}

\author{
Faouzi M. ${ }^{1 *}$, Ahmed B. ${ }^{1}$ and Saida M. ${ }^{2}$ \\ ${ }^{1}$ Department of Veterinary Sciences, ${ }^{2}$ Department of Agronomy, Faculty of Science and Life, \\ University Chadli Ben Jdid, El Tarf, Algeria, 'Corresponding: fouzi_vet16@yahoo.fr
}

(Received December 25, 2017; Accepted July 29, 2017)

\begin{abstract}
Research was undertaken to establish an inventory of ticks on dogs in the north east of Algeria. In the first aspect of study, a survey aims to identify of Ixodidae infesting the dogs in bioclimatic different areas and to determine the risk factors. This work took place between 2006 and 2012. The results of the collections show that all the dogs, which were the subject of this survey, are infested by ticks during the period between March and August in different areas of the northeastern of Algeria. Rhipicephalus sanguineus is the predominant tick species. It has been observed with a frequency of $88 \%$ in the area of ElTarf, $100 \%$ in Souk-Ahras, $95 \%$ in the Tébessa region and $72 \%$ in Guelma, (average of $89 \%$ ). Climatic conditions seem to play the essential role for this distribution of ticks. The other tick species collected are: Ixodes ricinus, Rhipicephalus turanicus, Haemaphysalis punctata and Hyalomma anatolicum. The latter were present with very low a proportion, which gives them the appearance of accidental parasitism in dogs. Rhipicephalus sanguineus has significant infestation intensity in spring and summer, peaking in August in the semi-arid region (Souk-Ahras). In humid regions (El-Tarf), the peak of infestation recorded by this arthropod is in April. The second aspect of study of the seasonal dynamics of Rhipicephalus sanguineus shows the seasonal nature (Spring-Summer) of the brown tick of dog.
\end{abstract}

Keywords: Ticks- Rhipicephalus sanguineus- dog- seasonal dynamics- Northeast Algeria Available online at http://www.vetmedmosul.org/ijvs

$$
\begin{aligned}
& \text { دراسة جرد لانواع القراد المتطقل على الكلاب في شمال شرق الجزائر } \\
& \text { فوزي معطى الله'، احمد بن نخلة' و سعيدة معطى الله' } \\
& \text { 'قسم العلوم البيطرية، بقسم العلوم الفلاحية، كلية العلوم و الحباة، جامعة الثاذلي بن جديد، الطارف، الجزائر }
\end{aligned}
$$

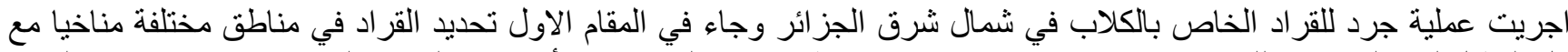

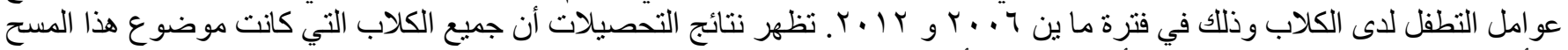

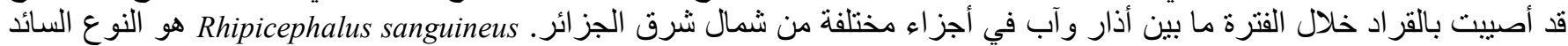

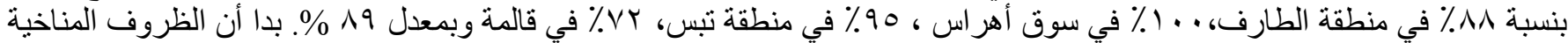

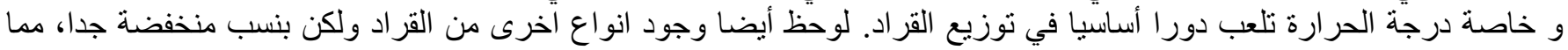
يشير الى صفة التطفل العرضي على الكلاب: Ixodes ricinus, Rhipicephalus turanicus, Haemaphysalis punctata and Hyalomma

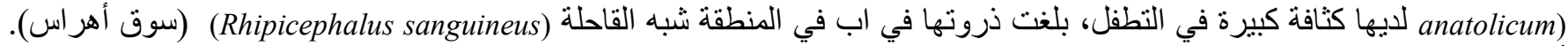

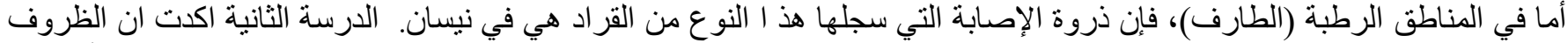

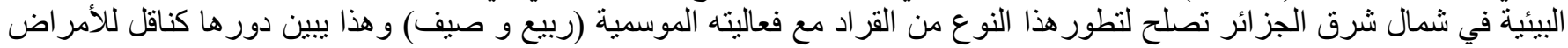
مما يشكل خطر ا على الكلاب و بالتالي مخاطر محتملة على على الانسان. 


\section{Introduction}

The dog infestation by ticks in Algeria is a frequent phenomenon considered as banal $(1,2)$. However, the vector role of these mites in the transmission of various pathogens (bacteria, parasites and viruses), gives them a great pathological importance $(3,4)$. This type of parasitism does not constitute a reason for recurrent clinic consultation of dogs. Most dog owners limit their actions to tick extraction despite the risk of infection by leaving their heads attached to the skin. Among ticks infesting the dog, Rhipicephalus sanguineus is the most widespread in the world. The brown dog tick is an ectoparasite of public health interest, due its capacity to carry and transmit a number of pathogens to humans (5). In Algeria, we do not have a clear idea on the distribution of dog ticks and the diseases they transmit, apart from published data on the prevalence of babesiosis, canine Ehrlichiosis and Rickettsiosis (1,6-8). This information is still limited in Algeria, whereas the epidemiological studies which support the emergence or reemergence of tick-borne pathogen in dogs around the world is necessary. Our work brings together various studies that have been done on this subject in order to understand the distribution of Ixodidae in northeastern Algeria.

\section{Material and methods}

\section{Study areas}

Work on the inventory of the Ixodidae fauna took place in different areas of north-eastern of Algeria (Figure 1), located on the bioclimatic floors; humid, sub-humid, semiarid and arid. The data are shown in Table 1.

Table 1: Characteristics of different areas of study

\begin{tabular}{|c|c|c|c|c|c|}
\hline \multirow{2}{*}{ Characteristics } & \multicolumn{2}{|r|}{ El-Tarf } & \multirow{2}{*}{ Souk-Ahras } & \multirow{2}{*}{ Guelma } & \multirow{2}{*}{ Tebessa } \\
\hline & El-Kala & Bouhadjar & & & \\
\hline Altitude (m) & 1 & 243 & 653 & 290 & 351 \\
\hline $\begin{array}{l}\text { Temperature } \\
\text { Average }\left(\mathrm{C}^{\circ}\right)\end{array}$ & 18,5 & 18 & 16,7 & 17,3 & 19,2 \\
\hline $\begin{array}{l}\text { Bioclimatic } \\
\text { floors }\end{array}$ & $\begin{array}{l}\text { Humid } \\
*_{\text {mediterneen }} \\
\text { climate }\end{array}$ & $\begin{array}{c}\text { Semiarid } \\
\text { *mediterneen climate }^{+} \\
+ \text {hot summer }\end{array}$ & $\begin{array}{c}\text { Semiarid } \\
*_{\text {mediterneen climate }} \\
+ \text { hot summer }\end{array}$ & $\begin{array}{c}\text { Subhumid } \\
*_{\text {mediterneen climate }} \\
+ \text { hot summer }\end{array}$ & $\begin{array}{c}\text { Arid } \\
* \text { desert climate } \\
+ \text { hot summer }\end{array}$ \\
\hline
\end{tabular}

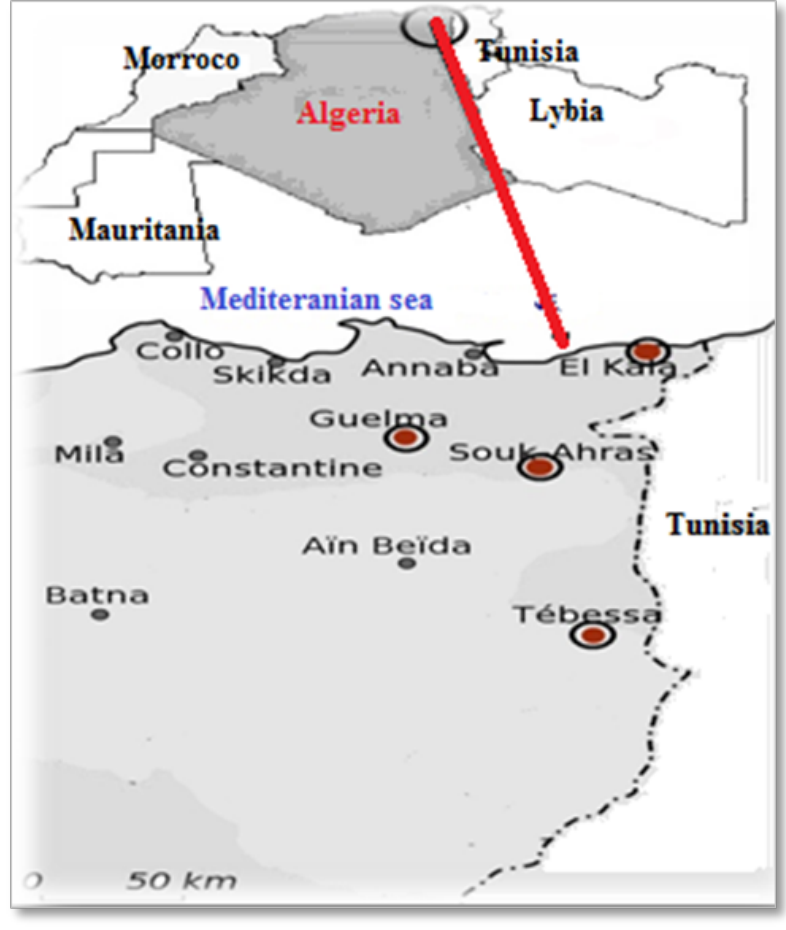

Figure 1: Geographical location of areas of study.

\section{Animal population}

The first study was conducted during a period from 2006 to 2012 and involved a total of 546 dogs. A survey protocol was produced and includes, in particular, memorial collection cards that identify each dog participating in the survey, as well as the samples taken. On these cards are recorded all information relating to age, sex and race. Finally, data related to the presence or absence of ticks, their location on the body of the animal, the general state of the animal have been reported. Dog treatments are not common practices in these areas. None of the dogs examined were wearing pestle collars.

Furthermore, another study was conducted at Sedrata area for a population of 15 dogs (local breed and sloughi breed) to get an idea about the seasonal dynamics of Rhipicephalus sanguineus.

\section{Research and collection of ticks}

The collection of ticks was carried out according to the areas between March and August, except for El-Mellah and Sedrata where the period was spread between January and September. This period of tick collection coincides with that of the activity of these mites. The collection was done once a month and involved an average of ten dogs 
randomly selected for the different areas, while the second study was conducted between April 2012 and March 2013.

The samples of ticks are placed in the tubes for alcohol (70\%) for good preservation and are transported to the parasitology laboratory of the Department of Veterinary Sciences (University of El-Tarf) for identification of tick species.

\section{Observation and identification of ticks}

For diagnosis, ticks are observed with an optical magnifier. These are placed in Petri dishes, handled by fine forceps. Before examination, the ticks must be dried (alcohol) for good observation. We depend the Ixodidae diagnosis key established by (9-11).

\section{Epidemiological indicators}

Basic concepts that can serve as epidemiological indicators are recorded with the formula allowing their calculation. Epidemiological Indicators Formulas:

Tick infestation rate $=$ Number of infested animals / Number of animals examined x 100.

Parasitic load (Intensity of infestation) $=$ Number of ticks / Number of parasitized animals.

Abundance of infestation (degree of infestation $)=$ Number of ticks collected / Number of animals examined x 100.

Relative abundance (frequency according to the species of tick) $=$ Number of tick species / Total number of ticks $\mathrm{x}$ 100.

\section{Statistical analyzes}

The Mann-Whitney test was used to compare parasite loads of ticks collected in different areas. The analyzes were carried out with SPSS Statistics software version 19. "ANOVA" test is used to study significant differences in results. Correlation test is also used for the influence of different study parameters.

\section{Results}

\section{First study: Collection report}

A study of the Ixodidae was conducted at different times in the different areas showed that out of 546 dogs examined, 480 were tick-infested ( a rate of $88 \%$ ). The number of ticks taken during this period is 3745 ; which represents an abundance of 7 ticks / dog examined and a parasite load of 8 ticks / dog infested. All dogs examined in the different regions are carriers of ticks, except the ElMellah area (El-Tarf) and Sedrata where 96/126 dogs and (90/120) parasitized respectively. It is interesting to note that in our study only adult ticks were encountered parasitizing dogs. The identification of collected ticks allowed the diagnosis of four genera (Rhipicephalus, Ixodes, Haemaphysalis and Hyalomma), with five parasitic species: Rhipicephalus sanguineus, Rhipicephalus turanicus, Ixodes ricinus, Haemaphysalis punctata and Hyalomma anatolicum. The specie $R h$. sanguineus has been found with a very high relative abundance ranging from 75 $\%$ in the El-Mellah; $76 \%$ in Sedrata (c) area to $100 \%$ in the Bouhadjar and Souk-Ahras areas. The other identified species, namely, Rh. turanicus, I.ricinus, Haemaphysalis punctata and Hyalomma anatolicum represented very low relative abundances tending towards.

\section{Parasitic association}

It should be noted here that the parasitic associations concerned in the areas of Negrine, Guelma, El-Kala and Souk Ahras, the species of $R$. sanguineus, I.ricinus and Hae. punctata whereas in the El-Mellah and Sedrata areas the association has been reported for Rh. sanguineus, $R h$. turanicus and Hy. Anatolicum. In addition, the different values found in these areas are very close:

Monoinfestation: $55 \%$ in El-Kala, $46 \%$ in El-Mellah, $83 \%$ in Negrine and $39 \%$ in Guelma and $80 \%$ in Souk Ahras.

Bi-infestation: $40 \%$ in El-Kala, $54 \%$ in El-Mellah, $17 \%$ in Negrine and $35 \%$ in Guelma and $15 \%$ in Souk Ahras.

Tri-infestation: $5 \%$ El-Kala, $83 \%$ in Negrine, $26 \%$ in Guelma and $5 \%$ in Souk-Ahras.

\section{Factors of receptivity}

Preferred sites: It has been reported that $70 \%$ of ticks attached on the ears. They were also found with low proportions in the inguinal region (24\%) and to a lesser degree in the limbs, abdomen and head with respective rates of $4 \%$ and $2 \%$.

Sex: It has been noted that the population of female ticks with a number of 2311(58\%) exceeds those of males with 1434 ticks (42\%). There was a slight predominance of female ticks for $R$. sanguineus with $56 \%$ (1802/3188), then a majority of female ticks for $R h$. turanicus $(83 \%$ female against $17 \%$ male). There are also a few more females' ticks for Hae. punctata with a rate of $65 \%$, which is not the case for I.ricinus, which found more male than female ticks with respective proportions of $60 \%, 40 \%$. $H y$. anatolicum identified are males.

Altitude: It has been observed that Rh. sanguineus has the lowest infestation intensities (4 to 5) at very low altitudes in areas near the sea (El-Kala, El Mellah). The highest values were noted in areas $200 \mathrm{~m}$ and above. Thus, for example, the highest intensity of 9 corresponds to an altitude of $800 \mathrm{~m}$ which characterizes the rarea of SoukAhras. 
It has been recorded also, intensities of 8 in Guelma (290 altitude); 9 in Tebessa $(351 \mathrm{~m}$ ) and 9 for Bouhadjar (243 m).

A positive correlation was found between altitude and parasite tick load during all study months $(r=0.807015>$ $0)$. This means that the intensity of infestation of dogs by $R h$. sanguineus is high in highland areas.

Bioclimatic stage: It turns out that the intensity of infestation of dogs by $R h$. sanguineus is high in semi-arid and arid bioclimatic zones where it reaches values ranging from 8 to 9 . On the other hand, intensity decreases. In subhumid to wet bioclimatic regions, in particular El-Kala and El-Mellah with respective values of 4 and 5 .

With regard to the other species (Rh. turanicus, $I$. ricinus, Hae. punctata and Hy. anatolicum), these have been observed either in the bioclimatic stages; sub-humid to humid and arid.

A positive correlation is found between the bioclimatic stage and the intensity of the infestation $(r=0.65837906>$ 0 ). Regarding the other tick species, we noticed that their presences with low intensity are compatible with medium and low altitude zones situated between 1 and $350 \mathrm{~m}$ (ElKala, El-Mellah, Guelma, Tebessa).

\section{Second aspect of the study}

The study of seasonal dynamics of population of 15 dogs during one year shows the following result (table 2, figures 2,3 ).

The distribution of ticks is not homogeneous in all age groups (. A high parasite load of 12.4 was recorded for 10 to 12 month old dogs. A negative correlation was found $(r=$ - 0.30) between the prevalence and the sex and age factors of the dogs.

In our study; it was found that the parasitic load of $R h$. sanguineus was higher in Sloughi breed dogs (11.7 ticks / dog) (out of $7 \mathrm{dogs}$ ); then for the local breed; we could record a load of 7.4 ticks / dog (out of a total of 8 dogs). A negative correlation was recorded $(r=-0.50)$ between the prevalence and the breed factor of dogs.

Note that parasitism by ticks is mostly located at the ears with a high rate of $83.2 \%$. Very low rates are recorded at the level of the inguinal region and the limbs $(11.4 \%$ and $5.4 \%$ respectively).

For a total number of 166 ticks ( 3 larvae and 10 nymphs identified in March), the morphological identification allowed finding of the following parasitic species: $R h$. sanguineus, Rh. turanicus and Hae. punctata with respective relative abundances of $80 \%, 18 \%$ and $2 \%$. The tick population is represented by $56 \%$ of females and $44 \%$ of males. Rh. Sanguineus infests dogs with a parasitic load of 9 ticks / dog infested.

A variation of the parasite load of these mites collected on the dogs is observed during the 12 months of study (Table 2). Dogs in the Sedrata area show a high intensity of infestation with $R h$. sanguineus between July and September with a peak value of 2 ticks / dog in August. In these months, we do not notice a high humidity but an increase in temperature was very remarkable. heavy rain seems to be a factor favoring the presence of $R h$. sanguineus. Also, the humidity does not seem to be a factor for the activity of this parasitic species. There are very highly significant differences between dogs' parasite loads for each month $(\mathrm{p}=0<0.001)$.

Correlation with rainfall was significant $(\mathrm{P}<0.05)$ in spring, summer and autumn 2012, but not in winter, because rainfall is seasonal and abundant (mean $800 \mathrm{~mm}$ per year) from May to October. Temperature is fairly stable in spring, summer and autumn (mean $21^{\circ} \mathrm{C}$ ), but not during winter. Therefore, we only found a correlation between prevalence and temperature $(p<0.05)$ during winter. There were significant differences between these seasons. However, there were significant differences $(p<0.05)$ between winter and remaining seasons.

Table 2: Intensity (load) of dogs infested in Sedrata

\begin{tabular}{ccccccccccccc}
\hline \multicolumn{11}{c}{ Number of dogs infested and intensity } \\
\hline Months & April & May & June & July & August & Sept & Oct & Nov & Dec & Jan & Feb & March \\
Ticks & 2012 & 2012 & 2012 & 2012 & 2012 & 2012 & 2012 & 2012 & 2012 & 2013 & 2013 & 2013 \\
\hline \multirow{2}{*}{ Rh. $s$} & 1,4 & 1,5 & 1,6 & 2,1 & 2,3 & 1,9 & 1,3 & 1,4 & 1 & 00 & 00 & 1,7 \\
& $(11 / 8)$ & $(12 / 8)$ & $(21 / 13)$ & $(29 / 14)$ & $(32 / 14)$ & $(23 / 12)$ & $(5 / 4)$ & $(7 / 5)$ & $(1 / 1)$ & $/$ & $/$ & $(10 / 6)$ \\
Rh. $t$ & 1,5 & 1 & 1,5 & 1 & 1,3 & 1,3 & 1 & 00 & 00 & 00 & 00 & 00 \\
& $(3 / 2)$ & $(6 / 6)$ & $(6 / 4)$ & $(4 / 4)$ & $(8 / 6)$ & $(5 / 4)$ & $(1 / 1)$ & & & & 00 & \\
Hae.p $p$ & 00 & 00 & 00 & 1,5 & 1 & 00 & 00 & 00 & 00 & 00 & 00 & 00 \\
& $/$ & $/$ & $/$ & $(2 / 1)$ & $(1 / 1)$ & $/$ & $/$ & $/$ & $/$ & $/$ & $/$ & $/$ \\
\hline
\end{tabular}

Sept: September- Oct: October- Nov: November- De: December- Jan: January- Feb: February. 


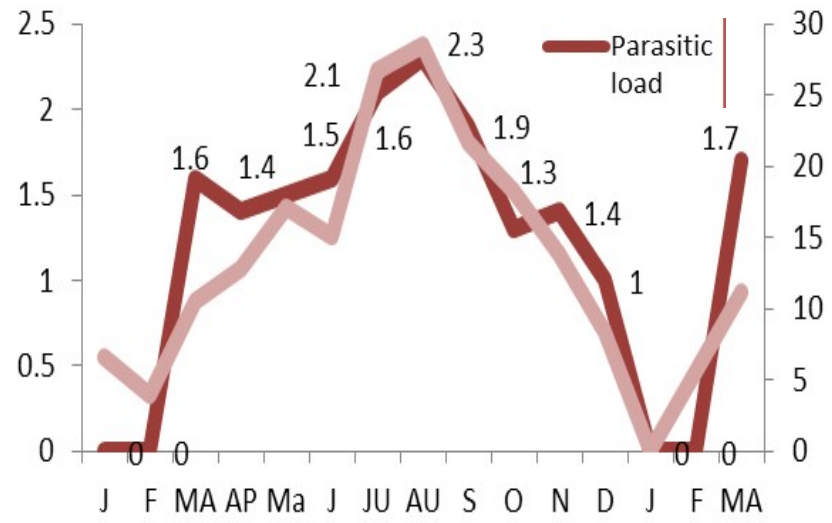

Figure 2: Variations in parasite load /Temperature.

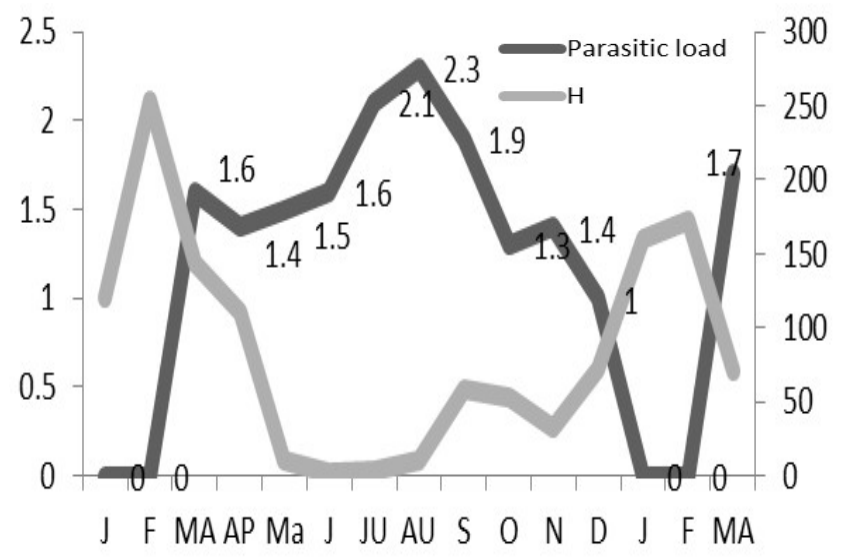

Figure 3: Variations in parasite load / Humidity.

\section{Discussion}

\section{First aspect of the study}

In the light of the results presented on the collections of ticks in the northeastern areas of Algeria, it turns out that the infestation of dogs is important, it was indeed counted 3745 ticks, all species combined, collected from 480 individuals in the different areas thus giving a total parasite load of 8 ticks / infested dog.

On the other hand, all the dogs examined between March -August, proved to be carriers of ticks, which represents an infestation rate of $100 \%$.

This systematic infestation of the canine population in the extreme northeastern regions of Algeria seems to be due to the lack of interest of the owners on the application of acaricidal treatment to their animals. Rh. sanguineus is the most common tick found in dogs in all these areas. It is found with very high relative abundances reaching values in the different areas. This high frequency of $R h$. sanguineus makes this animal its preferential host. This mite is rightly called the dog's common tick $(7,12)$.

This result is in agreement with others studies in the world. Survey in four cities in India (13) showed there were two genera of ticks: Rhipicephalus and Haemaphysalis, also in Indonesian and from 950 samples of ticks, $R h$. sanguineus was the only determined (14). (15) reported the total predominance of this tick in Italy and the same result was brought in Nigeria (16).

This tick is a good example of parasite globalization to its ubiquitous distribution which has clearly been facilitated by dog movements with their owners or trough trade (17).

In Europe, Rh. sanguineus adult parasitize dogs, ungulates and man, while the immature stages feed on rodents, hedgehogs and other small mammals (18). In contrast, some authors reported that the immature stages of this tick are most commonly involved in human parasitism (18-20). This approach is in agreement with the results of our study (even with a collection not meticulous because of the aggressiveness of the dogs in the rural environment). In the same approach $(9,21,22)$ indicate that the majority of ticks of $R h$. sanguineus taken from dogs are adults.

In addition to Rh. sanguineus, the dog may be infested with other species such as I. ricinus, Hae. punctata, Rh. turanicus and Hy. anatolicum but with negligible relative abundances.

These tick species identified are among the species recorded in Morocco and Tunisia in a contribution to the catalog of ticks in this country $(22,23)$.

In Nigeria, (16) provided the presence of boophilus spp, Hyalomma spp and Rh. sanguineus (second position with $10 \%)$. The high prevalence of boophilus ( $88 \%$ ) on dogs in this region raises the question for the affinity of Rhipicephalus for dogs.

In the same sense, the absence of $R h$. sanguineus and in Great Britain (24) and in Hungary (25) asks the same question? Even with the presence of the dog tick "Dermacentor reticulates" that is not recorded in our study.

Although, this tick has been identified on dogs in Hungaria, Poland $(25,26)$ where the studied area corresponds to a temperate continental climate with some mid-mountain areas. In France, Rh. sanguineus was in second position after Ixodes ricinus (27).

This result is interesting for the probability of transmission of pathogens, since in I. ricinus mainly transmits Lyme disease, whereas D. reticulatus and $R h$. sanguineus play an important role in babesiosis $(7,20)$.

For Hy. anatolicum, it is reported as an infective tick of the dog with Rh. sanguineus in Pakistan (28) what gives the principle of parasitic combination that has to be studied for certain parasites?

About the others parasites, we can say that the environment (climate and cohabitation with other animals: 
ruminants especially) where the dogs lived can play a role in the infestation accidentally by ticks.

In our study, the forest richness of the El-Kala, ensuring the thermal and hygrometric regulation favors the presence of ticks I. ricinus and Hae. punctata. Dogs can be infected with ticks whose, the humidity playing an important role for the survival of these parasites. Also, I. ricinus can be found in low altitude areas as it is found at high altitude areas with abundant vegetation for at least part of the season (29).

During their parasitic life, dog ticks are fixed, according to our observations, largely on the ears, a lesser degree on the inguinal region and the limbs. However, in 2003, (27) reported a majority of ticks taken from the head, neck and secondarily from the back and side. Also, in 2012, (16) reported that the most preferred sites of tick attachment in decreasing order were head, neck and legs. The majority of ticks $(91.7 \%)$ were adults, which were identified to species level, the others were nymphs.

In the same subject, in 2010, (7) reported that $R h$. sanguineus ticks can attach everywhere on the dog, but the head (particularly on ears), interdigital spaces, back, inguinal region, and axilla are among their preferred attachment sites.

Although ticks Rh. sanguineus have short hypostome and attach more superficially in comparison with others ticks, they can attach firmly to the host's skin.Also; this distribution on the body corresponds, according to these same authors to the parts primarily in contact with the vegetation in which the animals circulate (30).

Male and female tick populations coexist on different parts of the dog's body with a large number of female. This can be explained by the fact that according to the data of the literature, female ticks, particularly those of $R h$. sanguineus, once engorged with blood remain on the animal for 3 weeks and males even longer (9).

In addition, dogs are heavily infested with $R h$. sanguineus in areas exceeding $200 \mathrm{~m}$ as Bouhadjar (243 meters), Guelma (290 metere), Tebessa (351 meters) and Souk-Ahras (800 meters). In these areas, parasite loads vary between 8 and 9 ticks / infested animal. In areas near the sea ( $1 \mathrm{~m}$ above sea level), the parasite loads are lower and reach respectively 4 and 5 at El-Kala and El-Mellah. A positive correlation between parasite loads and infestation intensity was thus verified $(\mathrm{r}=0.6583706>0) . R h$. sanguineus, thermophilic mite appears to be much more adapted to semi-arid (Souk-Ahras) and arid (Tebessa) climates; the area of Souk-Ahras receiving a rainfall often less than $800 \mathrm{~mm}$ / year constitutes a favorable environment for the development of this parasite.

At the same time, Rh. sanguineus is adapted to warm temperatures (optimum of $24-27^{\circ} \mathrm{C}$ ) and a low degree of humidity $(31,32)$, as is the case of arid areas (Tebessa).
These observations are in agreement with those reported in Libreville (33) concerning the evaluation of dog infestation by ticks in the region of Libreville in Gabon, known for its hot climate. Indeed, he highlighted a parasitic load of 7.3 ticks / dog infested. Also in 1999, (34) has revealed that the stable temperature in summer, spring and autumn in the Cuernavaca City makes a favorable environment for the infestation of dogs by Rh. sanguineus.

Finally and in addition to favorable weather conditions noticeably the temperature and the cohabitation the dogs with ruminants especially that favor the parasitism by $R h$. sanguineus, the predominance of this specie makes its important tropism for dog, and we can say that the brown tick is undoubtedly the most important species from the veterinary standpoint. While, the infection the dog with others ticks (I. ricinus, Hae. punctata, Rh. turanicus and Hy. Anatolicum) can only be considered accidental (7).

All that confirmed to us that $R h$. sanguineus (endophilic, monotropic tick), able to survive in outdoor environments, if the climatic and environmental conditions meet in some areas $(7,18)$.

\section{Second aspect of this study}

This study also showed there was no relationship between the breed of $\operatorname{dog}$ (Local end Sloughi breeds) with a degree of infestation of ticks $(\mathrm{P}>0.05)$. Similar results were reported in the Ashton Court Estate-UK, that factor of dog races/breeds did not affect the dog tick infestations (35).

Despite that, the high prevalence in Sloughi dogs can be explained by the short hairs characteristic of this breed of dog, which facilitates attachment and parasitic aggression.

Also, the infestation is more revelant in puppies, this can be explained by factor of immunity is low compared to adults (also to observe in El-Kala, Bouhadjar).

The study of seasonal distribution of Rh. sanguineus ticks on dogs, in Sedrata, confirms our results previous and gives the seasonal aspect of the dog's infection by the brown tick.

The identification of immature stages in March (even a small number) shows the importance of the triphasic cycle of this mite which reinforces this preferential parasitism for the $\operatorname{dog}(8)$.

As observed in most tick species, the host seeking stages of Rh. sanguineus are under the influence of climatic conditions, such as temperature and relative humidity (36). On the other hand, the development of feeding stage depends exclusively on the availability of the specific host $(7,36)$. According to the weather station, during the experiment, the mean temperature in Sedrata ranged from 4 (February) to $38,5^{\circ} \mathrm{C}$ (August), the relative humidity from 41 (August) to $77 \%$ (December and February) and the rainfall from 2 (June) to $172 \mathrm{~mm}$ (February).

The temperature seems to be the most important factor responsible for the parasitic evolution of $R h$. sanguineus. 
As such, in south of Italy 2010, (15) reported that the population (adult) of these mites increased during these months (July - August).

In despite the relative humidity within, and mainly the high temperatures, and the constant presence of dogs provided ideal conditions to the development of $R h$. sanguineus ticks.

\section{Conclusion}

Different areas of north east of Algerian have environmental conditions that favour the development and maintenance of $R h$. sanguineus ticks throughout the year. The study can provide a basis for additional work aiming at a strategic control programme for dogs in the study areas.

This situation may be a threat to dogs in view of the important role of $R h$. sanguineus as a vector of canine Babesiosis and Ehrlichiosis (13, 24, and as a possible risk for humans Furthermore the modern techniques of PCR are necessary for a better understanding of the epidemiology of this tick and vector diseases in Algeria.

\section{Reference}

1. Matallah F, Benakhla A, Medjouel L, Matallah S. Tick infestation of dogs and Prevalence of canine babesiosis in the north-east of Algeria; area of El-Tarf. Am Eurasian J Sustainable Agricul. 2012;6(3):126134.

2. Matallah F, Medjouel L, Benakhla A. Détection des pathogènes vectorisés, Rickettisia massiliae et Ehrlichia canis, par Rhipicephalus sanguineus chez des chiens ruraux dans le Nord- est algérien (Région d'El-Tarf). Revue Africaine de Santé et de Productions Animales. 2013;E.I.S.M.V. de Dakar.

3. Bourdeau P. Les tiques d'importance vétérinaire et médicale, 1re partie, principales caractéristiques morphologiques et biologiques et leurs conséquences. Point Vét. 1993;25:13-26.

4. Sonenshine DE. Biology of ticks.- Oxford: Oxford University Press; 1991;pp:482 .

5. Palmas C, Bortoletti G, Conchedda M, Contini C, Gabriele F, Ecca AR. Study on immunobiology in ectoparasites of public health interest: Rhipicephalus sanguineus. Parassitol. 2001;43:29-35.

6. Bitam I, Parola P, Matsumoto K, Rolain JM, Baziz B, Boubidi SC, Harrat Z, Belkaid M, Ddidier R. First Molecular Detection of $R$. conorii $R$. aeschlimannii, and $R$. massiliae in Ticks from Algeria. Ann NY Acad Sci. 2006;1078:368- 372.

7. Dantas-Torres F. Biology and ecology of the brown dog tick, Rhipicephalus sanguineus. Parasit. Vectors. 2010;3:26.

8. Donatien A. et Lestoquard F., État actuel des connaissances sur les Rickettsioses animales. Arch. Inst. Pasteur d'Algérie. 1937;15:142187.

9. Estrada- Peña A, Bouattour A, Camocas JL, Walker AR. Ticks of domestic animals in the Mediterranean region: a guide to identification of species- Zaragoza: University of Zaragoza, ITG Library, 2004.pp:31.

10. Hillyard. Ticks of North-West Europe. Synopses of the British Fauna, edited by Barnes RSK and Crothers J.H; 1996;pp:178.

11. Pegram RG, Keirans JE, Clifford CM, Walker JB. Clarification of the Rhipicephalus sanguineus group (Acari, Ixodidae). II. R. sanguineus (Latreille, 1806) and related species. System Parasitol. 1987;10:2744.
12. Dantas-Torres F, Melo MF, Figueredo LA, Brandão-Filho SP: Ectoparasite infestation on rural dogs in the municipality of São Vicente Férrer, Pernambuco, Northeastern Brazil. Rev Bras Parasitol Vet. 2009;18:75-77.

13. Abd Rani PA, Irwin PJ, Coleman GT, Gatne M, Traub RJA. Survey of canine tick-borne diseases in India. Parasit Vectors. 2011;4:141

14. Hadi UK, Soviana S, Pratomo IRC. Prevalence of Ticks and TickBorne Diseases in Indonesian Dogs. J Veterinar Sci Techno. 2016;7:330.

15. Lorusso V, Dantas-Torres F, Lia RP, Tarallo VD, Mencke N, Capelli G, Otranto D. Seasonal dynamics of the brown dog tick, Rhipicephalus sanguineus, on a confined dog population in Italy. Med Vet Entomol. 2010;24(3):309-315.

16. Adamu NB, Adamu JY, Salisu L. Prevalenc of ecto-, endo- and haemoparasites in slaughtered dogs in Maiduguri, Nigeria. Revue de Medecine Veterinaire. 2012;4(163):178-182.

17. Beugnet F, Marié JL. Emerging arthropod-borne diseases of companion animals in Europe. Vet Parasitol. 2009;163:298-305.

18. Gilot B, Laforge ML, Pichot J, Raoult D. Relationships between the Rhipicephalus sanguineus complex ecology and Mediterranean spotted fever epidemiology in France. Euro J Epidemiol. 1990;6:357362.

19. Carpenter TL, McMeans MC, McHugh CP. Additional instances of human parasitism by the brown dog tick (Acari: Ixodidae). Journal of Medical Entomology. 1990;27:1065-1066.

20. Estrada-Peña A, Jongejan F. Ticks feeding on humans: a review of records on human-biting Ixodoidea with special reference to pathogen transmission. Experimental and Applied Acarology. 1999;23:685-715.

21. Bouattour A. Clé dichotomique et identification des tiques (Acari: Ixodidae) parasites du bétail au Maghreb. Arch Inst Pasteur Tunis. 2002;79:43-50.

22. Bouattour A, Darghouth MA, Daoud A. Distribution and ecology of ticks (Acari: Ixodidae) infesting livestock in Tunisia: an overview of eight years field collections. Parasitologia.1999;41(Suppl):5-10.

23. Bailly-Choumara H, Morel PC, Rageau J. Première contribution au catalogue des tiques du Maroc (Acari, Ixodoidea). Bull Soc Sci Phys Nat Maroc. 1974;54:71-80.

24. Smith FD1, Ballantyne R, Morgan1 ER, Wall R. Prevalence, distribution and risk associated with tick infestation of dogs in Great Britain. Med Vet Entomol. 2011;25:377-384.

25. GaborFoldv'ri*, Robert Farkas. Ixodid tick species attaching to dogs in Hungary. Medical and Veterinary Entomology. 2005;129:125-131.

26. Mirosław M. Michalski. The occurrence of Dermacentor reticulatus (Acari: Ixodida) on dogs in Olsztyn. Annals Parasitol. 2016;62 suppl:114.

27. Zenner L, Drevon E. Etude épidémiologique des populations de tiques rencontrées dans 12 clientèles de l'Ain et de la Haute-Savoie. Rev Méd Vét 2003;154:225-230.

28. Ul-Hasan M1, Abubakar M, Muhammad G, Khan MN, Hussain M. Prevalence of tick infestation (Rhipicephalus sanguineus and Hyalomma anatolicum anatolicum) in dogs in Punjab, Pakistan. Vet Ital. 2012;48(1):95-8.

29. Perez C, Rodhain F. Biologie d'Ixodes ricinus L. 1758. I. Ecologie, cycle évolutif. Bull Soc Pathol Exot. 1977;70:187-192.

30. Szabó MP, Cunha TM, Pinter A, Vicentini F. Ticks (Acari: Ixodidae) associated with domestic dogs in Franca region, São Paulo, Brazil. Exp Appl Acarol. 2001;25:909-916.

31. Koch HG. Seasonal incidence and attachment sites of ticks (Acari: Ixodidae) on domestic dogs in southeastern Oklahoma and northwestern Arkansas, USA. J Med Entomol. 1982;19(3):293-298.

32. Matallah F, Benakhla A, Bouattour A. Infestation du chien par Rhipicephalus sanguineus dans deux régions de l'extrême nord-est de l'Algérie. Revue d'élevage et de médecine vétérinaire des pays tropicaux. 2013;66(3):97-91

33. Moubamba D. Identification et distribution des espèces de tiques (Acari : Ixodidae) qui infestent les chiens à Libreville, Ann Méd Vét 2006;150:193-196. 
34. Cruz-Vazquez C, Garcia-Vazquez Z. Seasonal distribution of Rhipicephalus sanguineus ticks (Acari: Ixodidae) on dogs in an urban area of Morelos, Mexico. Exp Appl Acarol. 1999;23(3):277-280.

35. Jennett AL, Smith FD, Wall R. Tick infestation risk for dogs in a periurban park. Parasit Vectors. 2013;6:358.
36. Carla Cristina BL, Iracele Nogueira FI, Vilma Ferreira DE, Guido Fontgalland Coelho LI, Liliana Borges DM, Lígia Miranda Ferreira BII. Seasonal dynamics of Rhipicephalus sanguineus (Acari: Ixodidae) in dogs from a police unit in Goiania, Goias, Brazil. Cienc Rural. 2007;37:464-469. 